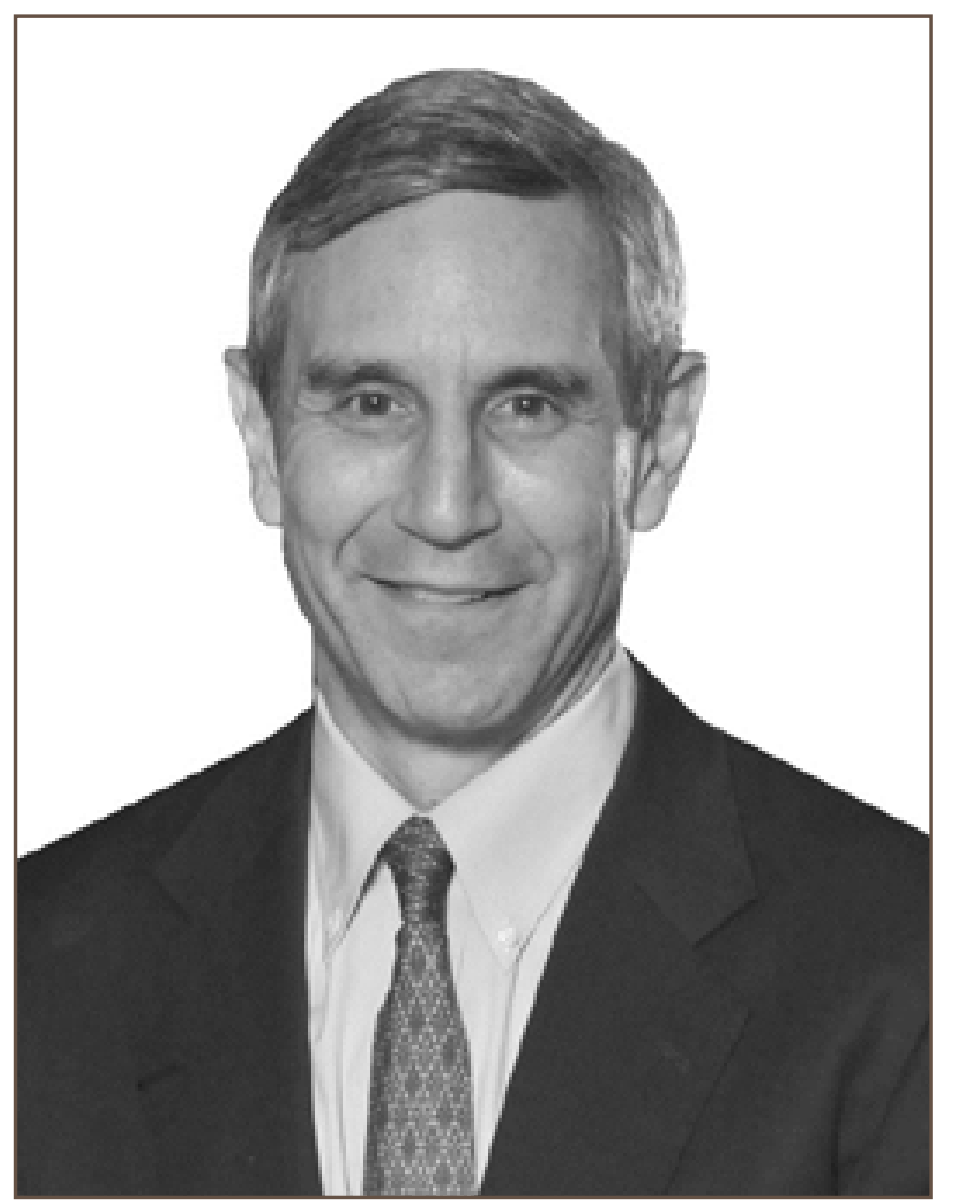

\title{
Richard Edelman
}

- Graduado (BA) pelo Harvard College e com MBA pela Harvard Business School

- Presidente e CEO da Edelman, organização internacional de relações públicas

- Membro do Conselho Diretor das organizações Ad Council, the Atlantic Council, the Children's Aid Society e 9/11 Museum.

- Membro do World Economic Forum e do PR Seminar

- Possuidor de grande número de prêmios e distinções

- E-mail:contato@edelman.com.br

\section{Comunicador: o Davi de todos os Golias}

\author{
Communicator: the David of all of the Goliaths
}

Comunicador: el David de todos los Goliats

Entrevistadores I Nara Almeida / Paulo Nassar / Luiz Alberto de Farias

- Da equipe de Organicom

Tradução do inglês | Nara Almeida

- Mestranda em Ciências da Comunicação pela ECA-USP

- Gerente de Planejamento Estratégico e Relações Institucionais da Aberje

\section{Foto}

\section{Extraída do portal da Edelman}


$\mathrm{P}$ ara Richard Edelman, presidente e CEO da Edelman, considerada a "agência da década" pelas organizações midiáticas Advertising Age e The Holmes Report, estamos vivenciando quatro grandes revoluções simultâneas, todas disruptivas: nos níveis de confiança dos clientes, na relação com o ritmo da inovação, na eficiência da propaganda e na implosão da mídia tradicional. As melhores marcas contemporâneas são parceiras na vida das pessoas, interpretando tendências sociais para desenvolver suas ofertas.

No contexto que define como "era da expressão", Richard, que tem graduação e MBA pela Harvard, entende que o core business da sua agência é solucionar problemas para os consumidores em nome das organizações. E, nesse processo, dois fatores são essenciais: a associação entre os grandes líderes globalmente e a comunicação, como diferencial das empresas.

Neste depoimento à Organicom, durante vinda ao Brasil para o encontro Lidercom CEOs promovido pela Aberje, Edelman que encabeçou a lista dos executivos mais poderosos da PRWeek (2013), foi reconhecido como o terceiro melhor CEO pela Glassdoor (2014) e entrou no Hall da Fama da Arthur W. Page (2014) - debate os desafios do Brasil, abordando temas como economia, confiança, tendências e mix da comunicação.

\section{Organicom - Qual é a sua visão atual sobre as relações públicas e a comunicação organizacional globais?}

Richard Edelman - Atualmente, temos um cenário no qual metade das agências não está crescendo ou tem observado apenas crescimento mínimo, enquanto a outra metade tem apresentado crescimento com dígitos expressivos. As áreas de negócio que mais têm crescido em comunicação são as relacionadas ao marketing e à comunicação digital. Enquanto isso, tem havido muita pressão sobre as áreas de assuntos corporativos e relações públicas das organizações. Entretanto, as agências que se especializam em tais práticas não estão crescendo tão rapidamente quanto aquelas que também se especializam em marketing e comunicação digital.

\section{Organicom - E quanto ao CCO, ou seja, ao diretor de comunicação corporativa, especialmente no Brasil?}

Richard Edelman - Os comunicadores têm um dos trabalhos mais difíceis, entre todas as diretorias atuais em todo o Brasil. Vender produtos e construir empresas nunca é fácil e apenas imagino a árdua batalha que os principais comunicadores brasileiros enfrentam, enquanto seus públicos são continuamente bombardeados com más notícias.

O ano 2016 foi extremamente desafiador, com a reputação do Brasil despencando a um ponto perigosamente baixo. A economia brasileira encolheu 5,4\%. 0 país, que estava conduzindo o crescimento dos Brics, caiu rapidamente. Há apenas cinco anos, a

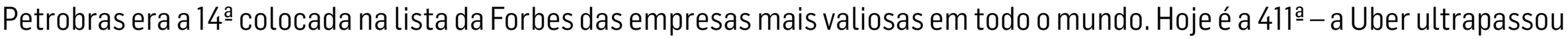
a Petrobras em valor de mercado. Nossa pesquisa Trust barometer mostra que, dentre a população de 27 países, a população brasileira tem um índice de confiança nas empresas sediadas em seu país de apenas 32\%, um dos mais baixos, à frente apenas de Índia e México. Compare essa confiança com 64\% para as empresas alemãs, canadenses e suecas. É um cenário terrível.

Mas, já vimos algo assim antes: nos Estados Unidos, entre 2008 e 2009. Empresas respeitadas como Citibank, AIG, GM caíram em desgraça, CEOs foram demitidos, o governo saiu ao resgate das corporações. Uma crise financeira e de habitação se seguiu e deve perdurar ainda pelos próximos anos. Quase 25\% dos afro-americanos e latinos perderam suas casas. Foi um 
choque de realidade, mostrando que o governo não tinha conseguido definir as orientações adequadas para as empresas e que os reguladores falharam em fazer cumprir a lei. A comunidade empresarial inteira deveria ter feito uma pausa, reavaliado e articulado, mas isso não aconteceu.

Os resgates do governo apenas exacerbaram o fosso entre os que têm e os que não têm. Os CEOs foram para o bunker, mantendo suas cabeças baixas e esperando a poeira assentar. Eles se concentraram exclusivamente em Wall Street, e tiveram início o corte de empregos, salários mais baixos e a terceirização - tudo e todos em nome da eficiência e de balanços sólidos.

Oito anos desse círculo vicioso deixaram os Estados Unidos em uma rebelião populista, na qual o público tem canalizado a sua frustração e o anseio de liderança a candidatos presidenciais como Bernie Sanders e Donald Trump, chocando a estabilidade em dois extremos. Sem dúvida, 2016 é o equivalente brasileiro da crise financeira de 2008 nos Estados Unidos. Mas a história no Brasil não precisa ter o mesmo desdobramento. É possível fazer melhor.

\section{Organicom - Como reverter esse cenário?}

Richard Edelman - Antes, é preciso olhar mais atentamente para três revoluções simultâneas, para entender melhor o cenário diante de nós.

Primeiro, o crescente gap de influência entre governo e empresas. Não é surpresa que a confiança no governo brasileiro, por parte tanto da elite quanto do público em geral, é surpreendentemente baixa. 0 governo tem a confiança de apenas $30 \%$ do público informado e de $21 \%$ da população em geral. Na verdade, o Brasil ocupa o penúltimo lugar na confiança no governo entre os 27 países pesquisados, contra uma média global de 42\%. Sem confiança no governo, o público não só quer, mas espera que as empresas liderem.

Em segundo lugar, em função da desconfiança nas instituições, há uma nova dispersão de autoridade para os indivíduos. A pesquisa Trust Barometer mostra que a pirâmide clássica de influência foi virada de cabeça para baixo, com a influência agora repousando na massa da população, mesmo com o poder permanecendo nas mãos da elite. Há uma ascensão do populismo. 0 líder de governo e o CEO estão sendo substituídos pela "pessoa como eu", e os empregados irrompem como uma das mais críveis fontes de opinião.

\section{Dentre a população de 27 países, a população brasileira tem um índice de confiança nas empresas sediadas em seu país de apenas $32 \%$, um dos mais baixos, à frente apenas de Índia e México.}


Por fim, a mídia como a conhecíamos implodiu, como resultado do declínio da publicidade e da ascensão da internet. Os hábitos de consumo de mídia da população em geral mudaram. No Brasil, $82 \%$ da população cita o uso de sites de pesquisa e mídias sociais múltiplas vezes durante a semana, enquanto apenas $46 \%$ leem jornais e apenas $40 \%$ leem revistas. Para a população global, sites de pesquisas e mídias sociais são as mídias dominantes. Todo o modelo de negócios da mídia paga entrou em colapso. A publicidade, que vendia marcas tão efetivamente desde a II Guerra Mundial, agora se encontra em uma tempestade perfeita. Entre bloqueadores de anúncios, cliques fraudulentos e o advento do móbile, um terço dos millennials não vê nenhum anúncio. As marcas devem reconhecer que o eixo predominante de comunicação está agora na horizontal (peer-to-peer), não mais na vertical.

\section{Organicom - O que nós podemos fazer como comunicadores e como organizações?}

Richard Edelman - Como organizações, é preciso enfrentar o novo, e isso é fascinante. 0 público tem muita expectativa de que as organizações liderem, em vez do governo. Há uma nova expectativa em relação aos negócios: 80\% das pessoas acredita que é possível fazer dinheiro e melhorar a sociedade, simultaneamente. Além disso, apenas ganhar dinheiro já não é o suficiente; é preciso também melhorar ativamente a sociedade. As organizações têm a obrigação de demonstrar altos padrões éticos e provar continuamente que não estão interligadas de forma indecorosa com líderes do governo. $E$, finalmente, é necessário ser um bom empregador, tratar bem os funcionários e tomar posse de seu papel na vida das pessoas e das comunidades em que vivem. É preciso envolvimento e integridade.

Isso não é exclusivo para o Brasil; é uma tendência que vemos em todo o mundo. Mas, no Brasil, essa nova expectativa apresenta oportunidade de liderar, em um momento em que a marca nacional está sob o fogo no ambiente internacional. Se as empresas brasileiras querem jogar no mercado global, precisam mudar sua cartilha. Não é suficiente mudar o discurso; deve-se possuir responsabilidade para mudar a realidade. Isso significa instalar conselhos de administração com influência internacional, com especialistas bem reconhecidos, que trarão melhores práticas para o C-level. Isso significa foco no comprometimento, na transparência e na integridade.

Em minha opinião, o Brasil está em uma encruzilhada. Os líderes vão continuar a espiral para baixo ou forçarão uma reconsideração? Acredito que vocês têm a oportunidade de ser o país dos Brics que irrompe. Os escândalos têm testado a sua democracia e seus sistemas têm mostrado que podem suportar a pressão. Estamos testemunhando instituições judiciais fortes e independentes e imprensa livre no trabalho. Além disso, vemos que a sociedade brasileira apoia o processo, pedindo transparência e comportamentos éticos nos negócios e no governo. Estes são sinais de que o Brasil pode fazer melhor. $E$ este é o momento. Precisamos definir um novo Brasil no âmbito corporativo e recuperar a confiança no cenário nacional e internacional. Recuperar a narrativa e construir relacionamentos de longo prazo com os clientes não é apenas sobre seu posicionamento de negócio, é sobre o que seu negócio pode e deve fazer para resolver questões mais amplas.

\section{Organicom - Os líderes devem, então, comprometer-se com a sociedade para conquistar sua confiança?}

Richard Edelman - Esse contrato com a sociedade e a confiança estão diretamente ligados à reconquista da confiança. 0 público viu a promessa de futuro do Brasil, baseada em magnatas e na promessa de país do futuro, cair em meio a escândalos. Mas esse mesmo público também tem visto brasileiros no palco global, liderando algumas das empresas mais admiradas do mundo, como Carlos Alves de Brito na InBev ou Carlos Ghosn na Nissan. Ghosn ganhou o apelido de "Sr. Conserta Tudo" pela guinada que deu na Nissan e tem sido amplamente creditado por seu estilo de liderança 
transcultural que desafiou normas empresariais japonesas, enquanto ainda honra a herança das montadoras. Ele fez isso de forma transparente, anunciando seu plano e salientando uma cultura de meritocracia, abrindo o diálogo com as partes interessadas e assumindo responsabilidade sobre o sucesso da empresa.

Organicom - Que lições podemos aprender com o passado para transformar a crise em oportunidade e aproveitar este momento como ideal para a liderança brasileira?

Richard Edelman - Proponho um modelo para que o Brasil aproveite essa oportunidade e não siga os passos dos Estados Unidos da América: 1) seja um negócio baseado em princípios, empenhado em fazer bons negócios para a sociedade em geral; 2) comprometa-se com a governança e definir um modelo para a prestação transparente de contas; nomear membros de conselho internacionalmente reconhecidos e garantir sua autoridade para aprovar mudanças de modo transparente; perguntar-se acerca do que fazer para mudar o status quo e, em seguida, fazê-lo, medi-lo e pedir aos públicos feedbacks sobre o seu progresso; 3) colabore com empresas afins, reguladores e grupos cívicos; a ação coletiva pode construir um ambiente que permitirá o sucesso; 4) converse com seus funcionários, diga-lhes o que está acontecendo e deixe-os seguir adiante; os consumidores querem receber as mensagens de uma "pessoa como eu" e ninguém está mais bem preparado para levar essa mensagem do que seus próprios funcionários servindo na linha de frente do seu negócio; 5) o seu CEO não pode se esconder; pressione-o a representar algo além de números, buscando engajamento e integridade e contando a história maior por trás disso tudo; 6) reconheça que você precisa de mídia e conduza a sua história através de mídias próprias, ganhas e canais sociais, com uma dose saudável de mídia paga também para garantir que você possa chegar ao público certo. No ambiente de hoje, a empresa tem possibilidade maior do que qualquer instituição para mapear mudanças tangíveis e liderar.

Pense em como o sucesso da Samsung preparou uma onda para a Coreia do Sul crescer. Natura, Suzano e Votorantim, Banco Itaú, Embraer talvez sejam algumas das empresas que podem ajudar a pavimentar o caminho para a marca Brasil. Poderia ser uma empresa como a Odebrecht, que poderia buscar a confiança e conduzir um diálogo fresco em torno da transparência corporativa e prestação de contas. Ninguém está dizendo que o Brasil deve deixar sua cultura para trás. 0 Brasil é único, não é os Estados Unidos e nem deve ser. Eu sei e compreendo que o caos pode dar luz à criatividade, mas uma estrutura subjacente para incutir confiança é necessária para chegar ao próximo estágio de seu desenvolvimento. Ginga é uma maneira bonita e invejável para jogar futebol. Não é uma maneira de executar um negócio de confiança no cenário internacional. Mas o Brasil pode manter a sua cultura vibrante e transcender a lacuna de confiança. Em cinco

\section{Se as empresas brasileiras querem jogar no mercado global, precisam mudar sua cartilha. Não é suficiente mudar o discurso; deve-se possuir responsabilidade para mudar a realidade.}


anos, as empresas brasileiras poderão ser consideradas como as melhores em governança corporativa, em práticas de sustentabilidade, nas relações de trabalho etc. Muito melhor dentro do possível em um país que já não pode se esconder por trás do "país em desenvolvimento". o Brasil pode ganhar, mas apenas se os líderes agirem corretamente.

Organicom - A pesquisa "Edelman trust barometer"l de 2016 mostra um desnível surgindo entre a elite a as massas, no que diz respeito à confiança. 0 que isso significa para governos, negócios, instituições e mídia?

Richard Edelman - Esse é um fenômeno assustador. As elites pensam que está tudo bem, que a situação das coisas está boa. Enquanto, por outro lado, as massas discordam ferozmente. 0 ponto é que os dois lados estão se comportando e votando dessa forma. Isso é uma forma de populismo entre duas classes.

0 caso Brexit é um exemplo. 0 estudo Trust barometer de 2016 indicou previamente essa profunda divisão entre a população com alto patrimônio líquido e a população de baixa renda no Reino Unido. Existe um hiato de 32 pontos entre esses grupos na confiança nos negócios (67\% versus 35\%) e uma diferença de 28 pontos entre esses grupos na confiança no governo (54\% versus $26 \%$ ). Quanto a futuras perspectivas econômicas, $40 \%$ das famílias de baixa renda no Reino Unido acreditam que será pior em cinco anos, contra 13\% das famílias de alta renda. Olhando através do outro lado do vidro, apenas $20 \%$ das famílias de baixa renda acreditam que estarão melhores em cinco anos, enquanto $47 \%$ das pessoas com elevados rendimentos acreditam que as coisas estarão melhores.

A ofensiva sedutora defendendo a permanência na União Europeia parecia cair em ouvidos surdos. Apesar dos relatórios do Banco da Inglaterra, do Ministério das Finanças do Reino Unido, do Banco Mundial, do FMI e da OCDE sobre as terríveis consequências econômicas do Brexit, a opinião pública raramente se alterou. Apenas $37 \%$ dos eleitores acreditavam que 0 Reino Unido seria pior economicamente com a saída da União Europeia, contra 38\%, três meses antes. Nosso CEO no Reino Unido, Ed Williams, disse-me: "a campanha na Europa não melhorou as coisas. Uma das razões pelas quais as pessoas insistiam na saída era precisamente porque cada instituição nacional e internacional grande dizia o contrário, como se essas instituições quisessem proteger o status quo e manter a riqueza para si mesmos. Williams podia imaginar um eleitor pensando. É exatamente o que eles nos diriam, não?".

Anatole Kaletsky, um ex-mentor meu em Harvard e agora um jornalista financeiro no Reino Unido, escreveu: "0 referendo Brexit é parte de um fenômeno global, uma revolta populista contra os partidos políticos estabelecidos, predominantemente pelos mais velhos, mais pobres e menos escolarizados eleitores irritados o suficiente para derrubar as instituições existentes e desafiar políticos do establishment". Ele acredita que a raiva passou do foco de 2008 sobre os banqueiros para as elites de forma mais ampla.

O Reino Unido pode representar apenas 2,5\% do PIB global, mas o sinal que o Brexit envia ao mundo é profundamente angustiante. Ele sinaliza a mudança de comportamento de mídia de mainstream a social. Sinaliza a ascensão de um jornalismo emocional e de curto prazo, em detrimento de um mais racional e de longo prazo, com o Times de Londres sendo preterido por tweets. A pirâmide de influência é de fato virada de cabeça para baixo, com a influência movendo-se para a massa e as autoridades podendo sucumbir. Neste ambiente volátil, empresas terão de tomar a iniciativa de contar a sua própria história seja através de mídias ganhas ou de mídias próprias.

10 estudo global Edelman trust barometer mede o nível de confiança das sociedades no governo, nas empresas, nas ONGs e na mídia. Na sua 16ª edição, foi produzida pela Edelman Intelligence, braço de pesquisa da rede Edelman, e consistiu em entrevistas online realizadas entre outubro e novembro de 2015 em 28 países. Foram 33 mil entrevistados (28.000 do público em geral e 5.000 respondentes que se enquadram na categoria de público informado - possuem educação superior, hábito de consumir notícias diversas vezes na semana e acompanham temas sociais e políticos). Os resultados globais e o recorte brasileiro do estudo podem ser acessados integralmente no site da Edelman Significa. Disponível em: <http://www.edelman.com/insights/intellectual-property/2016-edelman-trust-barometer/>. Acesso em: 26 jul. 2016. 
Organicom - 0 estudo "Earned brand 2016"2 fala sobre conduzir os consumidores a uma fase "all in" do relacionamento. Como as empresas podem alcançar isso?

Richard Edelman - O índice confirma que, em média, os consumidores alcançaram o que chamamos de fase do "envolvido". Contudo, esses compradores indicam que estão dispostos a ir muito mais longe do que simplesmente comprar. Na verdade, eles sinalizaram o desejo de estágios mais profundos de conexão e relacionamento que quantificamos e definimos como do "empossado" ou "comprometido" com sua marca favorita. Nosso estudo mostra que uma clara maioria dos consumidores que alcança esses estágios vão, em primeiro lugar, comprar, permanecer fiéis, advogados e defender sua marca favorita. Estes relacionamentos mais fortes trazem benefícios muito almejados: 77\% adotam a inovação mais rapidamente; $79 \%$ pagam um preço premium; 82\% recomendam a marca através de likes e compartilhamentos; e 80\% a defendem contra os críticos. Em suma, os consumidores "comprometidos" trabalham por você.

Os profissionais de comunicação e marketing precisam reconsiderar o mix de marketing para incluir uma mistura de mídias pagas, ganhas e próprias a cada estágio do relacionamento com seus públicos. Os consumidores que estão nas fases de "empossado" e "comprometido" são consistentemente mais envolvidos por mídias ganhas e próprias do que pela mídia paga na comunicação. Em segundo lugar, o estudo mostra que as marcas podem lidar mais facilmente com as expectativas e desejos de seus clientes a partir do propósito, do storytellinge, principalmente, da escuta. Os comportamentos que atingiram as melhores notas no estudo Earned brands são, justamente: "agir com propósito", "contar uma história memorável" e "ouvir abertamente/responder seletivamente". Esses comportamentos e estratégias têm o maior potencial para habilitar um padrão mais comprometido de relacionamento do consumidor com a empresa, por meio de estratégias que impliquem colaboração, participação, valores e ações compartilhados. E é precisamente essa a diferença entre presentear os clientes com uma campanha e empoderá-los para aderirem a um movimento.

Organicom - Quais as novas ofertas e habilidades que os departamentos de relações públicas e os profissionais da área precisam desenvolver?

20 estudo Earned brand 2016 é uma pesquisa online global com 13.000 consumidores em 13 países, que examina a relação consumidor-marca em 18 categorias de marcas. Disponível em: <http://www.edelman.com/insights/intellectual-property/earned-brand-2016/>. Acesso em:26 jul. 2016.

\section{As empresas e seus profissionais precisam começar a se distanciar da ideia de profissionais puramente funcionais ou técnicos, sendo assessores, estrategistas e parceiros de negócios.}


Richard Edelman - As empresas e seus profissionais precisam começar a se distanciar da ideia de profissionais puramente funcionais ou técnicos, sendo assessores, estrategistas e parceiros de negócios. 0 destino de muitas das marcas atendidas por agências hoje, incluindo as marcas ao lado das quais trabalhamos, depende da capacidade de obter a cooperação do público para a inovação e estruturas unicórnio, de rápida geração de valor, como muitas marcas e comportamentos da economia compartilhada.

\section{Organicom - Quais as próximas tendências para marketing e relações públicas?}

Richard Edelman - Nós devemos reinventar o setor de marketing, e a comunicação de marketing é uma dessas reinvenções fundamentais ao mercado e à área como um todo. É preciso um mindset, um modelo mental voltado à comunicação de marketing. E isso requer a compreensão de que a reputação de uma organização não está e nem pode ser separada da sua marca. Como profissionais de comunicação, precisamos ajudar as empresas a pensarem seus objetivos, o que querem e o que precisam para fazer parte da sociedade.

Organicom - Como a academia e o mercado podem colaborar mutuamente para o desenvolvimento do professional de comunicação do futuro?

Richard Edelman - Os jovens precisam já sair da universidade com conhecimentos sobre programação e computação. Eles precisam de habilidades avançadas de linguagem visual, ser mais ágeis e espertos diante do mundo e precisam, ainda, dominar múltiplas linguagens. Eles já não podem mais ser unicamente estudantes de humanidades.

\section{Organicom - Você tem um lema ou uma filosofia de vida que define o seu trabalho?}

Richard Edelman-Eu gosto de me imaginar como o Davi dos Golias de todo o mundo. Eu gosto quando somos subestimados. Isso nos permite ser disruptivos. 